\title{
INFLUENCE OF THE PH OF CARDIOPLEGIC SOLUTIONS ON CELLULAR ENERGY METABOLISM AND HYDROGEN ION FLUX DURING NEONATAL HYPOTHERMIC CIRCULATORY ARREST AND REPERFUSION: A DYNAMIC ${ }^{31}$ P NUCLEAR MAGNETIC RESONANCE STUDY IN A PIG MODEL
}

Michael A. Portman, MD Anthony L. Panos, MD

Yun Xiao, MD

David L. Anderson, $\mathrm{CCP}^{\mathrm{b}}$

George M. Alfieris, $\mathrm{MD}^{\mathrm{b}}$

Xue-Han Ning, $M^{a}$

Flavian M. Lupinetti, MD
Objectives: The pH of cardioplegic solutions is postulated to affect myocardial protection during neonatal hypothermic circulatory arrest. Neither optimization of cardioplegic pH nor its influence on intracellular $\mathbf{p H}$ during hypothermic circulatory arrest has been previously studied in vivo. Thus we examined the effects of the $\mathrm{pH}$ of cardioplegic solutions on postischemic cardiac function in vivo, including two possible operative mechanisms: (1) reduction in adenosine triphosphate use and depletion of high-energy phosphate stores or (2) reduction of $\mathrm{H}^{+}$flux during reperfusion, or both. Methods: Dynamic ${ }^{31} \mathrm{P}$ spectroscopy was used to measure rates of adenosine triphosphate use, high-energy phosphate depletion, cytosolic acidification during hypothermic circulatory arrest, and phosphocreatine repletion and realkalinization during reperfusion. Neonatal pigs in three groups $(n=8$ each)-group $A$, acidic cardioplegia ( $\mathrm{pH}=6.8$ ); group $\mathrm{B}$, basic cardioplegia ( $\mathrm{pH}=7.8$ ); and group $\mathrm{N}$, no cardioplegia-underwent hypothermia at $20^{\circ} \mathrm{C}$ with 60 minutes of hypothermic cardioplegia followed by reperfusion. Results: Recoveries of peak elastance, stroke work, and diastolic stiffness were superior in group B. Indices of ischemic adenosine triphosphate use, initial phosphocreatine depletion rate, and $\tau$, the exponential decay half-time, were not different among groups. Peak $\left[\mathrm{H}^{+}\right]$in group A (end-ischemia) was significantly elevated over that of group B. The realkalinization rate was reduced in group $B$ compared with that in groups $\mathrm{A}(p=0.015)$ and $\mathrm{N}(p=0.035)$, with no difference between groups $\mathrm{A}$ and $\mathrm{N}(p=0.3)$. Cytosolic realkalinization rate was markedly reduced and the half-time of $\left[\mathrm{H}^{+}\right]$decay was increased during reperfusion in group $\mathrm{B}$. Conclusions: Superior postischemic cardiac function in group B is not related to alterations in ischemic adenosine triphosphate use or highenergy store depletion, but may be due to slowing in $\mathrm{H}^{+}$efflux during reperfusion, which should reduce $\mathrm{Ca}^{++}$and $\mathrm{Na}^{+}$influx. (J Thorac Cardiovasc Surg 1997;114:601-8)
$\mathrm{H}$ ypothermia provides the principal mode of myocardial protection during cardiac operations in the neonate. Although cardioplegia serves an ad-

From the Department of Pediatrics, Division of Cardiology, ${ }^{a}$ and Department of Surgery, Division of Cardiothoracic Surgery, ${ }^{b}$ University of Washington School of Medicine and Children's Hospital and Medical Center, Seattle, Wash.

Supported in part by grant R-29 HL47805.

Received for publication Dec. 20, 1996; revisions requested Feb. 19, 1997; revisions received May 30, 1997; accepted for publication May 30, 1997.

Address for reprints: Michael A. Portman, MD, Pediatrics, University of Washington, Box 356320, Seattle, WA 98195-6320.

Copyright (C) 1997 by Mosby-Year Book, Inc.

$0022-5223 / 97 \$ 5.00+0 \quad \mathbf{1 2 / 1 / 8 3 6 2 4}$ junctive role, optimization of the $\mathrm{pH}$ of cardioplegic solutions is a source of considerable controversy. Experimental support for clinical recommendations promoting an alkaline cardioplegia strategy is difficult to trace. ${ }^{1}$ Data obtained from several models have suggested that an acidic cardioplegia strategy may provide superior postischemic function. ${ }^{2-5} \mathrm{Un}$ fortunately, these studies were performed under various technical limitations and have not defined the mechanisms through which this putative superiority is provided. It has been suggested that acidic cardioplegia $\mathrm{pH}$ effectively lowers intracellular $\mathrm{pH}$, thereby reducing cellular metabolic needs and adenosine triphosphate (ATP) use. ${ }^{2}$ Surprisingly, meticulous myocardial intracellular $\mathrm{pH}$ measurements 
have not been performed during comparisons of the $\mathrm{pH}$ of cardioplegic solutions in normothermic or hypothermic models of circulatory arrest in an attempt to prove these hypotheses. Furthermore, the roles of hydrogen ion $\left(\mathrm{H}^{+}\right)$flux and transmembrane proton gradients have been relatively ignored during experiments dealing with cardioplegia. Conceivably, cardioplegia influences both extracellular and intracellular $\mathrm{pH}$, thus affecting this transsarcolemmal gradient and $\mathrm{H}^{+}$flux. Accordingly, $\mathrm{H}^{+}$fluxes could directly and indirectly affect $\mathrm{Na}^{+}$and $\mathrm{Ca}^{++}$fluxes, which are well linked to myocardial damage. ${ }^{6}$

The objective of this study was to examine the effect of the $\mathrm{pH}$ of cardioplegic solutions during hypothermic circulatory arrest and reperfusion on $\mathrm{H}^{+}$flux and postischemic function in a neonatal model in vivo. Cardioplegic solutions with $\mathrm{pH}$ at 6.8 and 7.8 were chosen for study because previous investigators have implied that myocardial protection can be affected by $\mathrm{pH}$ changes within this range. ${ }^{4}$ Additionally, we examined a control group without cardioplegia to determine whether cardioplegic solution provides an additive effect to hypothermia with respect to the parameters of interest. Dynamic, highly time-resolved ${ }^{31} \mathrm{P}$-nuclear magnetic resonance (NMR) spectroscopy, the principal investigative method in these studies, was applied to define cellular acidification and realkalinization rates in a clinically relevant model. Findings in these experiments support traditional alkaline $\mathrm{pH}$ strategies as providing superior postischemic function and demonstrate the operative mechanisms, which include a reduction in the realkalinization rate during reperfusion.

\section{Methods}

Cardiopulmonary bypass and surgical procedures. Animals used in this study were handled in accordance with institutional and National Institutes of Health animal care and use guidelines. Neonatal pigs (aged 24 to 31 days; weight 10 to $15 \mathrm{~kg}$ ) were sedated with intramuscular injection of ketamine $10 \mathrm{mg} / \mathrm{kg}$, atropine $0.05 \mathrm{mg} / \mathrm{kg}$, and xylazine 0.2 to $0.4 \mathrm{mg} / \mathrm{kg}$ ), intubated, ventilated with room air and oxygen, and given an intravenous dose of $\alpha$ chloralose $(40 \mathrm{mg} / \mathrm{kg})$. The aorta and the right atrial appendage were cannulated and cardiopulmonary bypass was instituted with the use of a circuit equipped with a membrane oxygenator (Minimax, Medtronic, Minneapolis, Minn.) and pediatric reservoir bag. Dextran 40 (500 $\mathrm{ml}$ ) was used to prime the cardiopulmonary bypass circuit. A snare was placed around the ascending aorta distal to the aortic valve. A catheter was placed through the right carotid artery with the tip just proximal to the aortic snare for instillation of cardioplegic solution. A catheter tipped with a highly compliant and inflatable latex balloon was inserted into the ventricular chamber via a small incision in the left ventricular apex. A $2 \mathrm{~cm}$ flexible radiofrequency coil was sutured to the lateral wall of the left ventricle.

Cardiac function. Pressure-volume curves were constructed by recording the pressure within the intraventricular balloon as the balloon was sequentially inflated from a zero volume in $1 \mathrm{ml}$ increments from $1 \mathrm{ml}$ to $10 \mathrm{ml}$. The atria were paced at 150 beats/min and afterload kept constant by maintaining mean aortic pressure between 50 and $60 \mathrm{~mm} \mathrm{Hg}$ through the bypass pump. Peak elastance and diastolic stiffness were determined from the respective slopes of the peak systolic and end-diastolic pressure curves. Recruitable stroke work was calculated as the area of the constructed pressure volume curve.

NMR measurements. After transfer of the pig into the magnet, the surface coil was tuned to $81 \mathrm{MHz}$ and matched to $50 \mathrm{ohms}$. NMR data were collected with the use of a General Electric spectrometer (General Electric Company, Fairfield, Conn.) operating at 4.7 tesla. Shimming was performed with the use of the ${ }^{1} \mathrm{H}$ free induction decay at $200 \mathrm{MHz} .{ }^{31} \mathrm{P}$ spectra were obtained by means of a cardiac gating sequence. Fully relaxed spectra were first obtained with the use of an approximate 16-second interpulse delay. Pulse width in a one-pulse sequence was then optimized according to the phosphocreatine and inorganic phosphate signal with the use of a 0.5 - to 0.6 -second interpulse delay. Spectra were then collected in 16-second blocks. This interpulse delay with 30 to 40 acquisitions per block served to increase overall signal intensity, but especially enhanced intracellular inorganic phosphate peak intensity. Relaxed spectra served as the reference for relative peak area calculations performed with the least squares analysis program. ${ }^{7}$ Intracellular $\mathrm{pH}$ was determined from the chemical shift difference inorganic phosphate-phosphocreatine using calibration curves for intracellular $\mathrm{pH}$ versus chemical shift at $37^{\circ}$ and $20^{\circ} \mathrm{C}$ adapted from Swain and associates. ${ }^{8}$ As a rapid transient change in cardiac temperature can affect intracellular $\mathrm{pH}$ measurement by NMR, cardioplegic solution was instilled at the temperature of the heart $\left(20^{\circ} \mathrm{C}\right)$.

Protocol. Pressure-volume curves were constructed before shimming and recording of baseline NMR data at $37^{\circ} \mathrm{C}$. Central cooling was initiated via the bypass circuit and completed to $20^{\circ} \mathrm{C}$ within 20 minutes. Baseline spectra were obtained, followed by rapid asanguination into the bypass circuit. Three experimental groups $(n=8$ in each) were used: group $N$, no cardioplegia; group $A$, acidic cardioplegia; and group B, basic cardioplegia. The aortic snare was immediately tightened and a $20 \mathrm{ml} / \mathrm{kg}$ dose of cardioplegic solution was infused into the aortic root in groups $\mathrm{A}$ and $\mathrm{B}$. The cardioplegic solution $\left(20^{\circ} \mathrm{C}\right)$ consisted of an electrolyte solution (Plasma-Lyte A) with added potassium chloride so that the composition (in milliequivalents per liter) was $\mathrm{Na}^{+} 140, \mathrm{~K}^{+} 45, \mathrm{Mg}^{++} 3$, $\mathrm{Cl}^{-} 104$, acetate 27 , and gluconate 23 and was adjusted to $\mathrm{pH} 6.8$ for group $\mathrm{A}$ and to 7.8 with sodium bicarbonate for group $\mathrm{B}$. These $\mathrm{pH}$ values were temperature corrected to $37^{\circ} \mathrm{C}$. The insulated bore of the magnet maintained temperature at $20^{\circ} \mathrm{C}$. Circulatory arrest for 60 minutes was followed by reperfusion at $20^{\circ} \mathrm{C}$ for 20 minutes, rewarming for 20 minutes to $37^{\circ} \mathrm{C}$, and functional analyses were repeated. All temperatures were confirmed with 

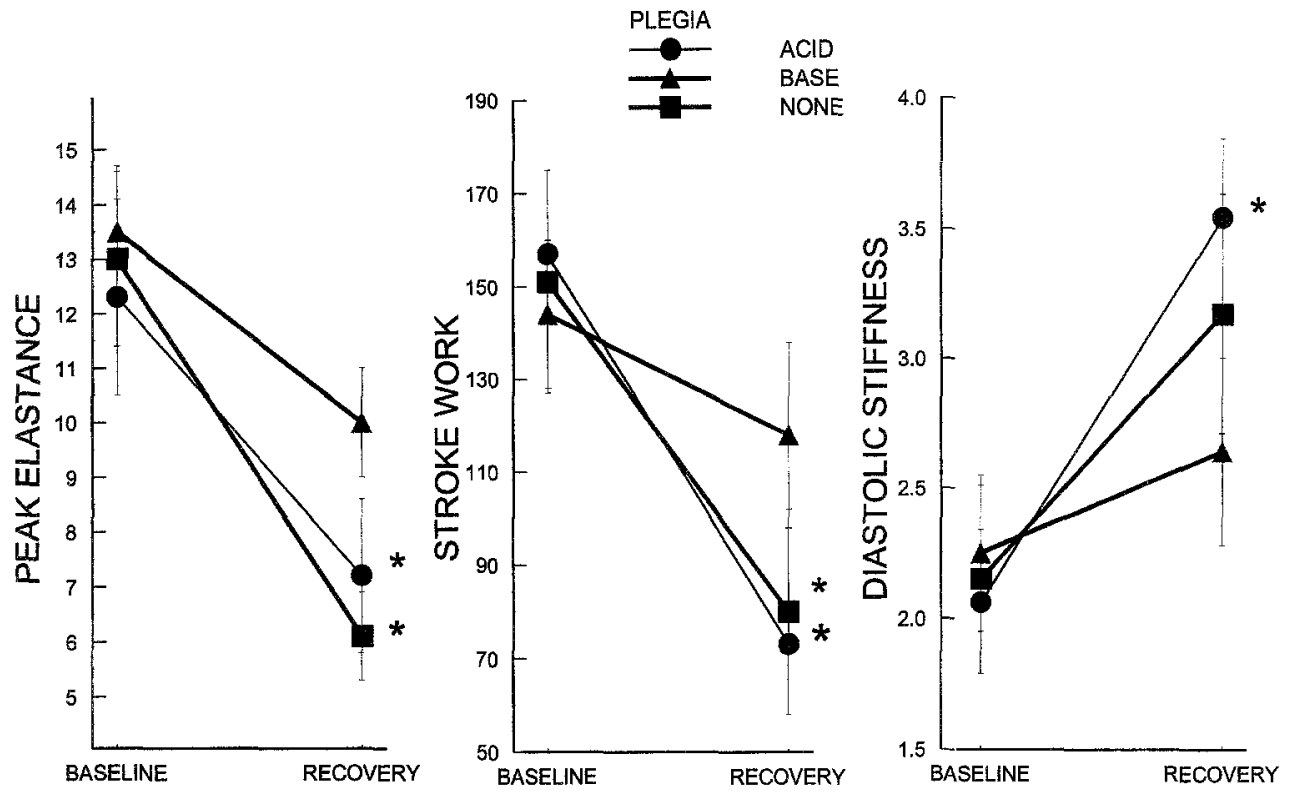

Fig. 1. Functional parameters for each experimental group are shown: $A C I D$, acidic cardioplegia; $B A S E$, basic cardioplegia; NONE, no cardioplegia. Units of measurement for peak elastance and diastolic stiffness are $\mathrm{mm} \mathrm{Hg} \cdot \mathrm{ml}^{-1}$ and for stroke work $\mathrm{mm} \mathrm{Hg} \cdot \mathrm{ml}$. ${ }^{*}$ Significant differences versus group $\mathrm{B}$. There are no significant differences between groups $\mathrm{A}$ and $\mathrm{N}$ (see text). Data are reported as means \pm standard deviations.

an esophageal temperature probe positioned behind the heart both within and without the magnet.

Statistical analyses. Data were evaluated with repeated-measures analysis of variance within groups and single-factor analysis of variance across groups. When significant $F$ values were obtained, Scheffe's test was used to distinguish which groups differed significantly from one another. Phosphocreatine and ATP data are reported as relative to baseline peak areas. Rapid alterations in concentrations of these high-energy phosphates and intracellular $\mathrm{H}^{+}$during ischemia and reperfusion have been shown to follow exponential patterns. ${ }^{9-11}$ The initial ascending or descending portions of these exponential curves have been demonstrated to approximate linear functions, and their slopes are regarded as reaction rates. Analyses of specific rates are detailed in the Results section. Linear regression analyses and exponential fitting of these serially acquired NMR data were performed with the use of the commercial curve analysis package provided with Axum 4.0 (Trimetrix Inc., Seattle, Wash.). All descriptive data in the Results section are reported as means \pm standard deviation. A $p$ value $<0.05$ was considered significant.

\section{Results}

Cardiac function. Baseline and recovery functional parameters are illustrated in Fig. 1 for the three groups. Postischemic conditions were identical to preischemic conditions with respect to paced heart rate and aortic pressure maintained by the flow pump. Compared with preischemic values, all groups showed changes in nearly all functional parameters after reperfusion $(p=0.01)$. The exception was diastolic stiffness, which increased after reperfusion in both the no-cardioplegia and acidic cardioplegia groups, but did not change significantly in the basic cardioplegia group $(p=0.2)$. No significant differences were noted between the acidic and no-cardioplegia groups for the three measured parameters. Recovery peak elastance and recruitable stroke work were better in the basic cardioplegia group $(p=0.03)$ than in either the acidic or no-cardioplegia groups. Postischemic diastolic stiffness, an index inversely related to diastolic function, was greater in the acidic group than in the basic cardioplegia group $(p=0.01)$, but no significant difference was observed between the basic and no-cardioplegia groups $(p=0.25)$.

Intracellular pH. Consistent with other studies, cooling from $37^{\circ}$ to $20^{\circ} \mathrm{C}$ was accompanied by an increase in intracellular $\mathrm{pH}$ in all groups ${ }^{8,9}:$ in group A from $7.27 \pm 0.11$ to $7.60 \pm 0.14$; in group $B$ from $7.25 \pm 0.14$ to $7.66 \pm 0.14$; and in group $\mathrm{N}$ from $7.26 \pm 0.14$ to $7.66 \pm 0.11$. Representative spectra are shown in Fig. 2. Fig. 3 demonstrates the typical course of $\left[\mathrm{H}^{+}\right]$during the ischemia protocol and emphasizes the differences in the speeds of acidifi- 


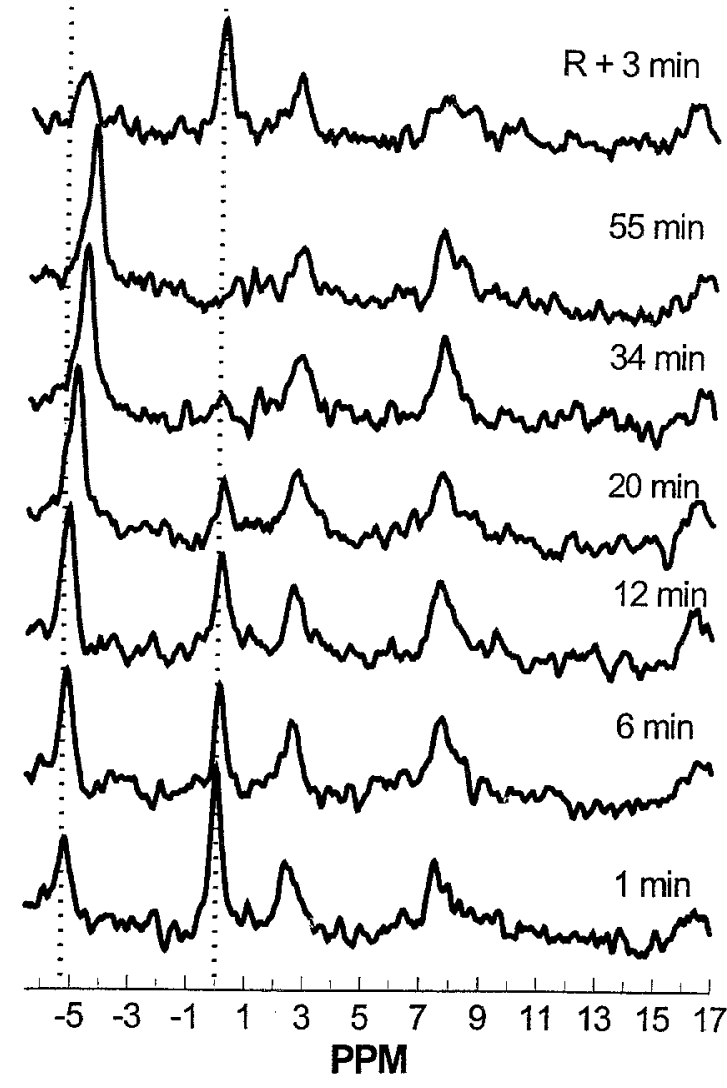

Fig. 2. ${ }^{31}$ P-NMR spectra from an individual experiment during ischemia and reperfusion. Spectra represent 16 seconds of acquisition ( 0.5 -second interpulse delay) with $5000 \mathrm{~Hz}$ sweep width, operative frequency $81 \mathrm{MHz}$. Processing includes $8 \mathrm{~Hz}$ line broadening. Time course in experiment is noted at right ( $R$ indicates reperfusion). Stippled lines represent initial phosphocreatine assignment at $0 \mathrm{ppm}$ and inorganic phosphate at $5.3 \mathrm{ppm}$. Note that inorganic phosphate peak increases in intensity and shifts up field (more positive) with respect to phosphocreatine during ischemia and shifts down field with reperfusion.

cation and realkalinization. $\mathrm{We}^{9}$ have previously reported an initial period of slight cellular alkalinization during circulatory arrest in sheep myocardium, in which the intracellular phosphate signal is greater than in the pig. The signal to noise in the present experiments precludes detection of this period, which is due to proton consumption in the forward creatine kinase reaction. Fig. 3 demonstrates that no increase in $\left[\mathrm{H}^{+}\right]$is observable during the initial 10 minutes of ischemia. Data were extracted to perform statistical analyses and define cellular $\mathrm{H}^{+}$flux: baseline, the average of four data blocks preceding circulatory arrest; peak $\left[\mathrm{H}^{+}\right]$, the average of four data blocks preceding reperfusion;
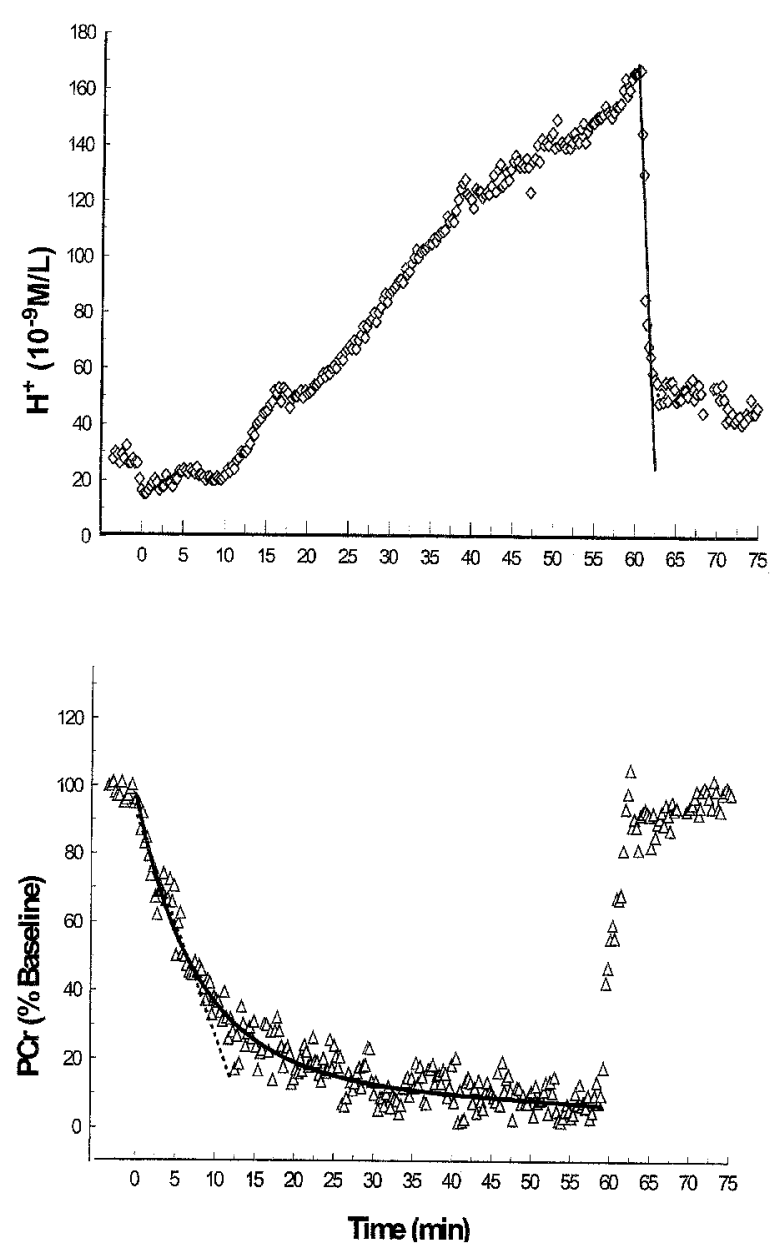

Fig. 3. Cytosolic $\mathrm{H}^{+}$and phosphocreatine $(P C r)$ changes during a 60 -minute ischemia and recovery at $20^{\circ} \mathrm{C}$ are shown for an individual experiment. Ischemia begins at 0 minutes and reperfusion at 60 minutes. The slope of the solid line $\mathrm{H}^{+}$plot represents the linear realkalinization rate. $\tau_{\mathrm{H}}$, the decay half-time, can be calculated by fitting an exponential curve to the reperfusion data. The curvilinear line results from such exponential fitting of phosphocreatine data; $\tau_{\mathrm{PCr}}$, equals 9.6 minutes in this particular experiment. The slope of the stippled lines represents the initial phosphocreatine depletion, which reflects the ATP use rate during ischemia.

and recovery $\left[\mathrm{H}^{+}\right]$, the average of four data blocks at the end of 20 minutes of reperfusion (Fig. 4). To refer to $\mathrm{H}^{+}$flux rates, baseline, peak, and recovery $\left[\mathrm{H}^{+}\right]$are noted in picomoles $\left(\mathrm{M} \cdot 10^{-9}\right)$ in Figs. 3 to 5 . Baseline values are nearly identical among the three groups, as are the recovery values. Peak $\left[\mathrm{H}^{+}\right]$ in the acidic cardioplegia hearts (end-ischemia) is significantly elevated over that of the basic cardioplegia group $(p=0.03)$. The differences between acidic cardioplegia and no cardioplegia $(p=0.15)$ 


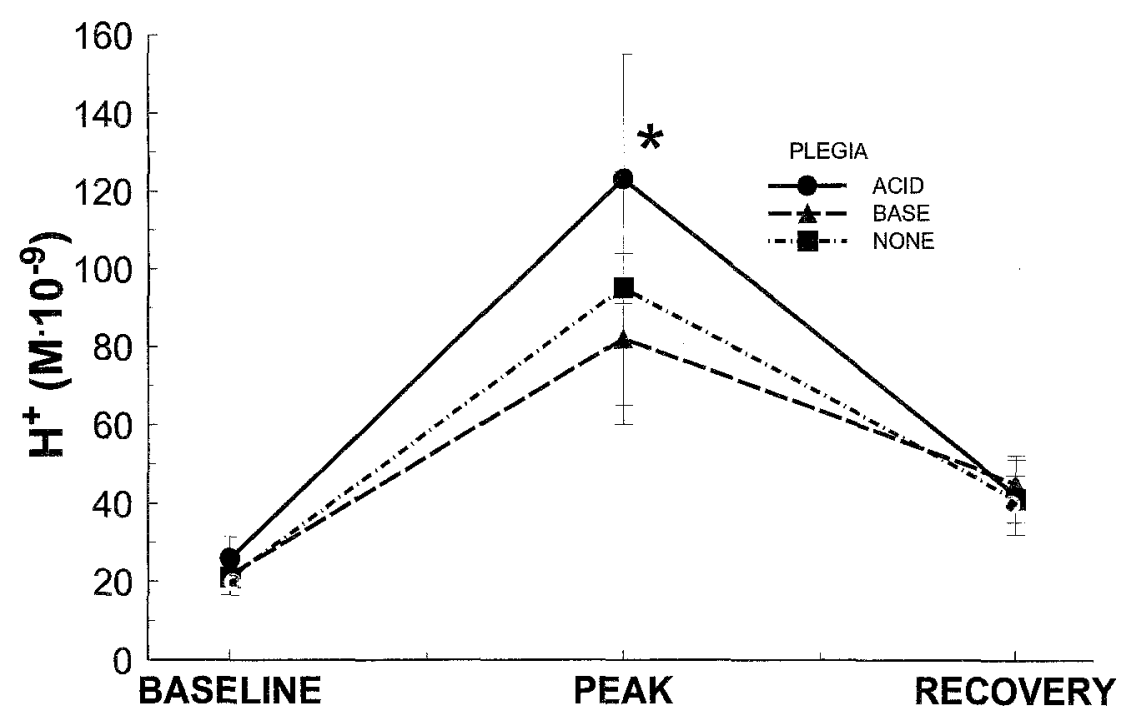

Fig. 4. $\mathrm{H}^{+}$concentration for each group is shown at different points in the protocol. Baseline is just before ischemia, peak is just before reperfusion, and recovery is 20 minutes after reperfusion (all at $20^{\circ} \mathrm{C}$ ). Data are reported as means \pm standard deviations.

and between basic cardioplegia and no cardioplegia $(p=0.28)$ do not reach significance. Traditional NMR studies, which use 2- to 4-minute data block averages, would not define the time course of realkalinization, ${ }^{10}$ which follows an exponential pattern. ${ }^{11}$ It is clear from the representative time course illustrated in Fig. 3 that the majority of $\mathrm{H}^{+}$movement occurs within the first 2 to 3 minutes of recovery. $\left[\mathrm{H}^{+}\right]$decay follows an exponential course. The rapid rate of the initial decline can be defined by the slope of the line derived from linear regression analysis by use of points from the first 2 minutes of recovery expressed as picomoles per minute. Range of the correlation coefficient squared $\left(R^{2}\right)$ for individual experiments was 0.81 to 0.89 . The entire course of recovery can be defined by exponential curve analysis to determine $\tau_{\mathrm{H}}$, the half-time of decay. The calculated initial realkalinization rates and $\tau$ values are shown in Fig. 5. The realkalinization rate is lower in group B than in groups A $(p=$ $0.015)$ and $N(p=0.035)$, with no difference between groups $\mathrm{A}$ and $\mathrm{N}(p=0.3)$. Similarly, $\tau_{\mathrm{H}}$ is significantly shorter in the acidic cardioplegia hearts ( $p=0.03$ vs $\mathrm{B}$ and $p=0.04$ vs $\mathrm{N}$ ), although the difference between groups $\mathrm{B}$ and $\mathrm{N}$ does not reach significance $(p=0.2)$. In summation, the $\mathrm{H}^{+}$flux data reveal that the $\mathrm{H}^{+}$extrusion is slower in hearts that have received basic cardioplegia, although the eventual $\left[\mathrm{H}^{+}\right]$attained is similar among the three groups.
High-energy phosphates. During the entire protocol no significant ATP change occurred in any group. ATP values at end-ischemia (percent baseline) for groups $\mathrm{A}, \mathrm{B}$, and $\mathrm{N}$, respectively, were $100 \pm 23,95 \pm 8$, and $96 \pm 8$. Initial rapid phosphocreatine depletion accompanies oxygen deprivation even under hypothermic conditions; there are no significant differences in these rates among the groups (Fig. 6), nor were there significant differences in $\tau$, half-time derived from the exponential phosphocreatine decay through ischemia (see Fig. 3 ); respective values for $\tau$ (minutes) for groups $\mathrm{A}, \mathrm{B}$, and $\mathrm{N}$ were $15.9 \pm 14,13.5 \pm 11$, and $22 \pm 14$. Phosphocreatine repletion is rapid compared with depletion in all groups (Fig. 6) and is slower in group $\mathrm{B}$ hearts ( $p=0.001$ vs groups $\mathrm{A}$ and $\mathrm{N}$ ).

\section{Discussion}

The influence of the $\mathrm{pH}$ of cardioplegic solutions on intracellular $\mathrm{H}^{+}$concentration and flux in vivo has not been previously examined. This study was performed in a model that emulates conditions present in developing myocardium undergoing hypothermic cardiopulmonary bypass and circulatory arrest. The functional analyses in these studies support the alkaline cardioplegia strategy used clinically. ${ }^{1}$ Contrasting data purporting an acidic cardioplegia strategy as beneficial have been obtained primarily in isolated heart preparations. Three such separate studies by Iannettoni, ${ }^{3}$ Bernard, ${ }^{2}$ Baker, ${ }^{4}$ 

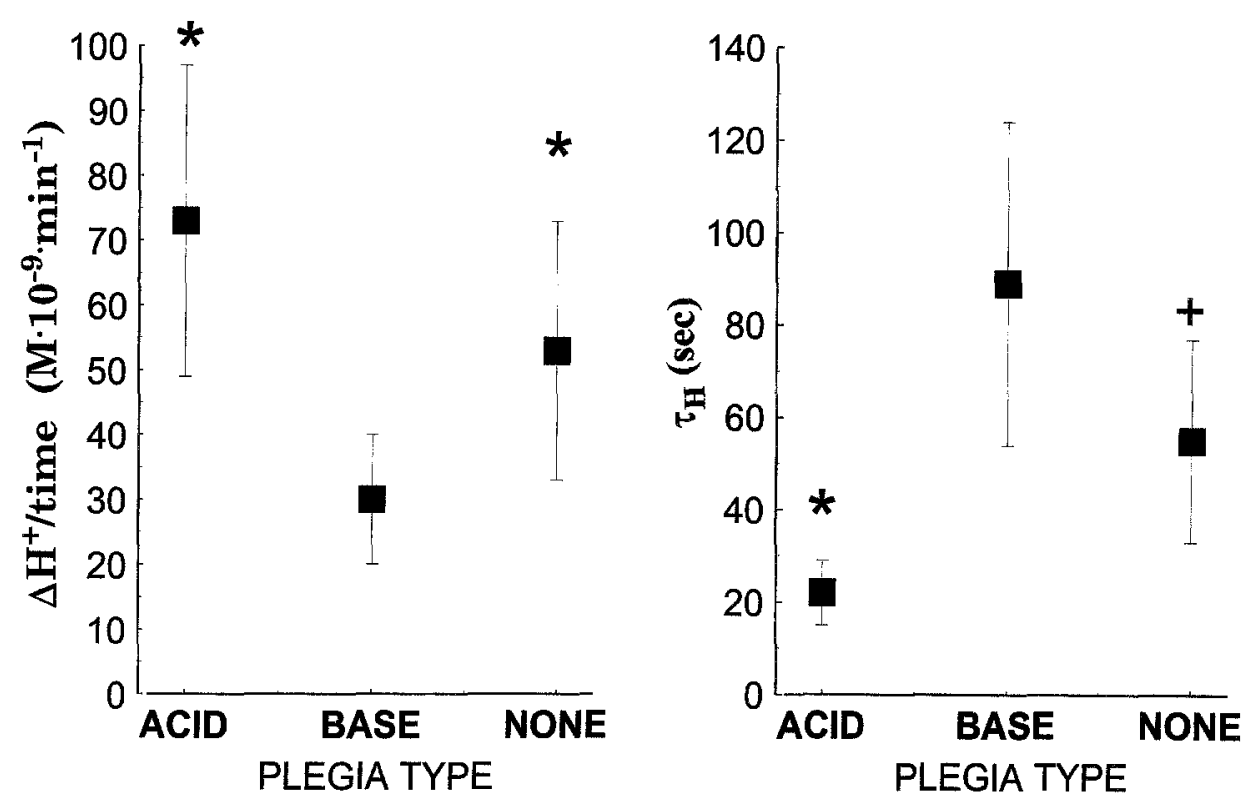

Fig. 5. The initial realkalinization rate $\left(\Delta \mathrm{H}^{+} /\right.$time $)$at reperfusion is shown in the first panel. $\tau$ is the halftime of $\left[\mathrm{H}^{+}\right]$decrease calculated from exponential curve fitting. These data together indicate that realkalinization is slower in BASE. *Differences versus BASE. ${ }^{+}$Differences versus ACID.

and their respective colleagues are frequently quoted and seem to challenge the concept that alkaline cardioplegia provides superior myocardial protection. These studies were technically limited and do not directly address the conditions currently considered in vivo. Specifically, Iannettoni and coworkers $^{3}$ varied buffer under normothermic conditions and did not isolate the $\mathrm{pH}$ of the cardioplegic solution. ${ }^{3}$ Bernard and coauthors ${ }^{2}$ did vary the $\mathrm{pH}$ of the cardioplegic solution used in mature rat myocardium, but functional results were equivocal in that acidic cardioplegia produced only transient superiority over basic cardioplegia with respect to postischemic function in the working heart preparation. Ostensibly, this group measured intracellular $\mathrm{pH}$ concurrent with ischemia and functional analyses. ${ }^{2}$ However, systematic error was unwittingly introduced into their intracellular $\mathrm{pH}$ data because temperature corrections for their chemical shift-pH calibrations were not performed. Subsequently, others have demonstrated that intracellular $\mathrm{pH}$ calculation without temperature calibration is inaccurate. ${ }^{8,12}$ Baker and colleagues ${ }^{4}$ provided evidence that the cardioplegia $\mathrm{pH}$ functional response follows a bell-shaped curve with the apex at $\mathrm{pH} 6.8$ in both immature and mature isolated working rabbit hearts. Their study offers the most compelling evidence in the isolated heart that a cardioplegic $\mathrm{pH}$ of 6.8 provides better postischemic function than a $\mathrm{pH}$ of 7.8. The model used in these experiments performed at $14^{\circ} \mathrm{C}$ was unique owing to extremely prolonged ischemic periods ( 3 to 4 hours). As intracellular $\mathrm{pH}$ was not monitored in Baker's study, the effect of this long duration of ischemia and profound hypothermia on $\mathrm{H}^{+}$flux even without provision of cardioplegia is unknown.

Support that acidic cardioplegia proffers superior myocardial protection in vivo has been provided by data obtained in only one study. Nugent and coworkers ${ }^{5}$ found such a beneficial effect in adult dogs undergoing 2 hours of cardiac arrest at $20^{\circ} \mathrm{C}$ with multiple-dose cardioplegia. Intracellular $\mathrm{pH}$ and $\mathrm{H}^{+}$ flux were not monitored in their study, and technical details such as temperature of reperfusate are not clearly provided. Thus it is difficult to perform analytical comparisons with that study. Conceivably, the differences are due to maturational or species effects, although these discrepancies may also be caused by the prolonged ischemia in their model.

The rapid phosphocreatine decline has been used as an index of ATP use during early ischemia or oxygen deprivation. ${ }^{7,9-11}$ Derivation and application of this index has been reviewed elsewhere. ${ }^{9,11}$ In brief, inasmuch as no aerobic ATP production occurs in early ischemia, phosphocreatine depletion represents total ATP use and follows a linear course until lactate production provides an anaerobic ATP component slightly later. ATP was held constant 
through these protocols, regardless of $\mathrm{pH}$ strategy, a result that corresponds with data obtained by Clark and coworkers ${ }^{13}$ in neonatal pigs during 1 hour of hypothermic circulatory arrest. Retention of ATP levels attests to the viability of the myocardium during these protocols. Thus early ischemic ATP use and depletion of high-energy phosphate stores throughout ischemia are not altered by the addition of cardioplegia in these studies, regardless of $\mathrm{pH}$ strategy. This finding is consistent with other studies, which could reveal no alterations in high-energy phosphate stores or myocardial oxygen consumption induced by cardioplegia superimposed on hypothermia. ${ }^{14}$ Clark and coworkers ${ }^{13}$ were able to demonstrate a decrease in high-energy phosphate store depletion, imposed by multiple doses of extremely cold cardioplegic solution during hypothermic circulatory arrest; however, this effect was likely induced by further temperature reduction, rather than by the cardioplegic solution itself. Phosphocreatine repletion is rapid in all three experimental groups. Although, phosphocreatine repletion rate was reduced in the basic cardioplegia group, this parameter is very dependent on the myocardial oxygen consumption rate in the aerobic heart. ${ }^{10}$ Conceivably, metabolic factors other than a discrepancy in myocardial oxygen consumption may also cause slowing in this rate. Unfortunately, oxygen consumption measurements would have added to the technical complexity of these experiments and were not performed. Thus this small reduction in phosphocreatine repletion rate in the alkaline cardioplegia group cannot be interpreted.

Generally, two hypotheses have been posed to explain the protective effect of cardioplegia during hypothermic circulatory arrest. The first states that cardioplegia alters myocardial energy metabolism and thus reduces ATP use and high-energy phosphate store depletion during hypothermic ischemia. The second hypothesis states that cardioplegia affects cellular $\mathrm{H}^{+}$fluxes and thus influences damaging ionic disturbances during reperfusion. These effects would be modified relative to the $\mathrm{pH}$ of the cardioplegic solution. Because deficits in myocardial energy metabolism during ischemia in the present model do not appear to be responsible for the superior postischemic function in the alkaline cardioplegia hearts, the second hypothesis requires consideration. Our data support the suggestion that cardioplegic solution administered during ischemia can modify reperfusion $\mathrm{H}^{+}$fluxes according to its $\mathrm{pH}$. Strategies that reduce the rate of cellular alka-

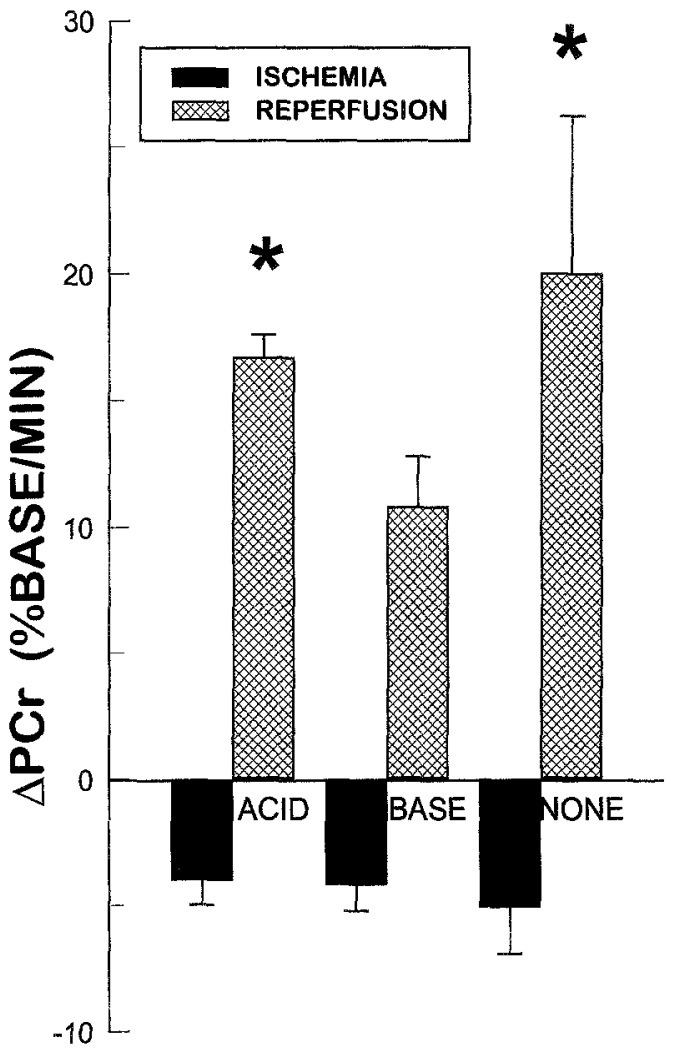

Fig. 6. Initial rates of phosphocreatine change $(\triangle P C r)$ are shown for ischemia and reperfusion in each group. The rate of decrease of phosphocreatine during ischemia is much slower than the increase during reperfusion. There are no significant differences in phosphocreatine change/time during ischemia. Phosphocreatine recovery is slower in BASE (see text). "Differences versus BASE. Data reported as means \pm standard deviations.

linization after ischemia consistently produce superior postischemic function. ${ }^{6,15,16}$ This rate appears to be sensitive not only to the intracellular $\mathrm{pH}$, but also to the transsarcolemmal proton gradient. ${ }^{17}$ Accordingly, reduction of extracellular $\mathrm{pH}$ in reperfusion medium has recently been a suggested mode of decreasing myocardial damage after ischemia. Kitakaze, Weisfeldt, and Marban ${ }^{6}$ showed that reperfusion with acidic medium in the isolated heart preserves function. Similarly, conditions leading to increased intracellular acidification before reperfusion exacerbate postischemic myocardial dysfunction. ${ }^{18}$ This corresponds to our experiments in which slightly lower intracellular $\mathrm{pH}$ just before reperfusion in hearts subjected to acidic cardioplegia provides more rapid realkalinization and more severe cardiac dysfunction. These findings imply that rapid washout of the extracellular medium with highly 
buffered and relatively alkaline medium such as blood activates cellular $\mathrm{H}^{+}$extrusion. The level of activation is presumably dependent on the intracellular $\mathrm{H}^{+}$concentration, as well as the transsarcolemmal proton gradient at reperfusion.

The relationship of cellular $\mathrm{H}^{+}$efflux to $\mathrm{Na}^{+}$and $\mathrm{Ca}^{++}$influxes, which mediate reperfusion damage, is well established. 6, 19, 20 Thus delayed cellular realkalinization induced by acidic reperfusion is associated with decreased $\mathrm{Ca}^{++}$influx and superior postischemic function. ${ }^{6}$ The $\mathrm{Na}^{+} / \mathrm{H}^{+}$exchanger probably represents at least one mechanism through which these ion fluxes are linked. Elevation of intracellular $\mathrm{H}^{+}$relative to extracellular $\mathrm{H}^{+}$promotes $\mathrm{Na}^{+} / \mathrm{H}^{+}$exchange across the sarcolemma, and this increased $\mathrm{Na}^{+}$influx stimulates cellular $\mathrm{Ca}^{++}$influx through $\mathrm{Na}^{+} / \mathrm{Ca}^{++}$exchange. ${ }^{19,21}$ Pharmacologic inhibition of the $\mathrm{Na}^{+} / \mathrm{H}^{+}$ exchanger has been shown even under hypothermic conditions to decrease intracellular $\mathrm{Na}^{+}$and intracellular $\mathrm{Ca}^{++}$during reoxygenation after hypoxia and thus preserve myocardial function. ${ }^{16}$

In summary, these data show that a basic cardioplegia strategy provides superior postischemic cardiac function in a model emulating clinically relevant conditions and durations of hypothermic circulatory arrest. The cardioplegia strategy does not alter the balance between high-energy phosphate production and use. The presumed mechanism for this superiority is a slightly lower intracellular $\mathrm{H}^{+}$at end-ischemia, which effectively reduces $\mathrm{H}^{+}$efflux during reperfusion. Although $\mathrm{Na}^{+}$and $\mathrm{Ca}^{++}$influx could not be measured in this study, other investigators have shown that an $\mathrm{H}^{+}$efflux is closely linked to these. The data in these experiments is consistent with those of studies showing that a reduction in these ion fluxes during reperfusion preserves postischemic myocardial function.

\section{REFERENCES}

1. Swan $H$. The importance of acid-base management for cardiac and cerebral preservation during open heart operations. Surg Gynecol Obstet 1984;158:391-414.

2. Bernard $M$, Menasché $P$, Canioni $P$, Fontanarava E, Grousett C, Piwnica A, Cozzone P. Protective effects of acidotic, glutamate-containing cardioplegic perfusate. $J$ Thorac Cardiovasc Surg 1985;90:235-42.

3. Iannettoni MD, Bove EL, Fox MH, Groh MA, Bollins S, Gallagher KP. The effect of intramyocardial pH on functional recovery in neonatal hearts receiving St. Thomas' Hospital cardioplegic solution during global ischemia. $\mathbf{J}$ Thorac Cardiovasc Surg 1992;104:333-43.

4. Baker J, Boerboom L, Olinger G. Age and protection of ischemic myocardium: Is alkaline cardioplegia appropriate? Ann Thorac Surg 1993;55:747-55.
5. Nugent WC, Levine FH, Liapis CD, Laraia PJ, Tsai C-H, Buckley MJ. Effect of the $\mathrm{pH}$ of cardioplegic solution on postarrest myocardial preservation. Circulation 1982;66(Suppl): II8-3.

6. Kitakaze M, Weisfeldt ML, Marban E. Acidosis during early reperfusion prevents myocardial stunning in perfused ferret hearts. J Clin Invest 1988;82:920-7.

7. Portman MA, Standaert TA, Ning X-H. The relation of myocardial oxygen consumption and function to high energy phosphate utilization during graded hypoxia and reoxygenation in sheep in vivo. J Clin Invest 1995;95:2134-42.

8. Swain JA, McDonald TJ, Robbins RC, Balaban RS. Relationship of cerebral and myocardial intracellular $\mathrm{pH}$ to blood pH during hypothermia. Am J Physiol 1991;260:H1640-4.

9. Portman MA, Eyster GE. Myocardial buffering capacity and high-energy phosphate utilization during hypothermic circulatory arrest and recovery in the newborn lamb in vivo. J Thorac Cardiovasc Surg 1994;108:946-52.

10. Portman MA, Standaert TA, Ning X-H. Developmental changes in ATP utilization during hypoxia and reoxygenation in the heart in vivo. Am J Physiol 1996;270:H216-23.

11. Blei ML, Conley KE, Kushmerick MJ. Separate measures of ATP utilization and recovery in human skeletal muscle. J Physiol 1993;465:203-23.

12. Kost GJ. pH standardization for phosphorous-31 magnetic resonance heart spectroscopy at different temperatures. Magn Reson Med 1990;14:496-506.

13. Clark BJ, Woodford EJ, Malec EJ, Norwood CR, Pigott JD, Norwood WI. Effects of potassium cardioplegia on highenergy phosphate kinetics during circulatory arrest with deep hypothermia in the newborn piglet heart. J Thorac Cardiovasc 1991;101:342-9.

14. Jessen ME. Neonatal myocardial oxygen consumption during ventricular fibrillation, hypothermia, and potassium arrest. Ann Thorac Surg 1996;61:82-7.

15. Hendryx M, Mubagwa K, Verdonck F, Overloop K, VanHecke $\mathrm{P}$, Vanstapel F, et al. New $\mathrm{Na}^{+}-\mathrm{H}^{+}$exchange inhibitor HOE 694 improves postischemic function and high energy phosphate resynthesis and reduces $\mathrm{Ca}^{2+}$ overload in isolated perfused rabbit heart. Circulation 1994;89:2787-98.

16. Anderson SE, Murphy E, Steenbergen C, London RE, Cala PM. Na-H exchange in myocardium: effects of hypoxia and acidification. Am J Physiol 1990;259:C940-8.

17. Grace AA, Kirschenlohr HJL, Metcalfe JC, Smith GA, Weissberg PL Jr, Vandenberg JI. Regulation of intracellular $\mathrm{pH}$ in the perfused heart by external $\mathrm{HCO}_{3}$ and $\mathrm{Na}\left({ }^{+}\right)-\mathrm{H}^{+}$ exchange. Am J Physiol 1993;265:H289-98.

18. Neely JR, Grotyohann LW. Role of glycolytic products in damage to ischemic myocardium. Circ Res 1984;55:816-24.

19. Tani M. Role of intracellular $\mathrm{Na}^{+}$in $\mathrm{Ca}^{2+}$ overload, and depressed recovery of ventricular function of reperfused ischemic rat hearts: possible involvement of $\mathrm{Na}^{+}-\mathrm{H}^{+}$and $\mathrm{Na}^{+} / \mathrm{Ca}^{2+}$ exchange. Circ Res 1989;65:1045-56.

20. Ward CA, Moffat MP. Modulation of sodium-hydrogen exchange activity in cardiac myocytes during acidosis and realkalinization: effects on calcium, $\mathrm{pH}$ and cell shortening. Cardiovasc Res 1995;29:247-53.

21. Karmazyn M, Moffat MP. Role of $\mathrm{Na}^{+} / \mathrm{H}^{+}$exchange in cardiac physiology and pathophysiology: mediation of myocardial reperfusion injury by $\mathrm{pH}$ paradox. Cardiovasc Res 1993;27:915-24. 